\title{
Midlatitude Static Stability in Simple and Comprehensive General Circulation Models
}

\author{
DARGAN M. W. Frierson \\ Department of Geophysical Sciences, University of Chicago, Chicago, Illinois
}

(Manuscript received 12 December 2006, in final form 2 July 2007)

\begin{abstract}
The static stability of the extratropical troposphere is examined in two atmospheric general circulation models (GCMs) over idealized boundary conditions, with emphasis on the role of moisture in determining the midlatitude stability. The determination of the static stability is compared within two models: an idealized moist model with simplified representations of radiative transfer and other physical processes, and a comprehensive GCM with full physics. The GCMs are run over a zonally symmetric, fixed sea surface temperature (SST) aquaplanet surface, with a multitude of SST distributions to study the response of the extratropical static stability over a wide parameter range.

In both models, the dry static stability averaged over the midlatitudes increases both with increases in the meridional temperature gradients, and with increases in the mean SST. These changes in static stability are compared with both moist theories and dry theories. Dry baroclinic eddy theories are invalid for the entire parameter range in the idealized GCM, and for much of the parameter range considered in the comprehensive GCM. A moist theory, on the other hand, works remarkably well in predicting the midlatitude stability over the entire parameter range for both models. These simulations give strong support for the influence of moisture on the thermal structure of the midlatitudes.
\end{abstract}

\section{Introduction}

When examining the zonally averaged climate of the atmosphere, one of the first quantities one notices is the change of temperature with height, or equivalently the static stability. Temperature decreases with height throughout the troposphere, but $(\partial T / \partial z)$ varies as a function of latitude and of height, as well as with season and climatic regime. The lapse rate/static stability is also of fundamental importance to the general circulation: it determines the buoyancy frequency of dry perturbations in the vertical, the speed of gravity waves, and the magnitude of the greenhouse effect (there is no greenhouse effect in an isothermal atmosphere). In the midlatitudes in particular, the static stability is a key component of any theory of the general circulation.

Static stability within the tropical troposphere is relatively well understood: there moist convection over warm waters sets the upper-tropospheric temperatures. The temperature structure there is thus approximately

Corresponding author address: Dargan M. W. Frierson, Dept. of Geophysical Sciences, University of Chicago, 5734 S. Ellis Ave., Chicago, IL 60637.

E-mail: frierson@geosci.uchicago.edu given by the moist adiabat (Xu and Emanuel 1989), and increases in dry static stability are thus expected with increasing temperatures. In the midlatitudes the determination of the static stability is much less well understood. Early theories relied on dry baroclinic eddy dynamics to understand the midlatitude static stability. Theories such as Stone (1978) and Held (1982) use different theoretical concerns to derive a similar constraint that relates the static stability to meridional temperature gradients:

$$
\theta_{z} \sim \frac{f}{H \beta} \theta_{y}
$$

with $\theta$ the potential temperature, $f$ and $\beta$ the Coriolis parameter and its gradient, and $H$ some depth scale, for example, the tropopause height or the scale height. The argument of Stone (1978) is based on the idea that dry baroclinic eddies are efficient enough to exactly neutralize the atmosphere to baroclinic instability. These "baroclinic adjustment" theories and their various subtleties are reviewed in Zurita-Gotor and Lindzen (2007). A theory similar to Eq. (1) but derived using potential vorticity diffusion considerations was shown to be accurate for an idealized dry general circulation model (GCM; Schneider 2004). Schneider's theory 
evaluates the meridional gradients at the surface instead of in the midtroposphere as is typical in baroclinic adjustment theories.

Recent studies have shown that the detailed predictions of the dry baroclinic eddy theories are not borne out in a full GCM (Thuburn and Craig 1997), in a dry primitive equation model under different forcing time scales (Zurita-Gotor 2008), or in observations (Juckes 2000). Focus has turned to moist convection as being a dominant factor in the determination of the midlatitude stability, as it is in the tropics (Juckes 2000). In this argument, moist convection occurs frequently within the warm cores of baroclinic eddies (Emanuel 1988; Korty and Schneider 2007), setting a minimum stability. The net moist stability of the midlatitudes is then determined by the standard deviation of the surface equivalent potential temperature, which can be related to meridional gradients through a mixing length closure. The end result relates the moist stability to surface equivalent potential temperature gradients (Juckes 2000; Frierson et al. 2006):

$$
\Delta_{z} \theta_{e} \sim \partial_{y} \theta_{e}
$$

where $\theta_{e}$ is the equivalent potential temperature, and $\Delta_{z}$ is an appropriate vertical difference.

We have studied the effect of moisture on midlatitude static stability in a simplified moist GCM in the study of Frierson et al. (2006). In that model, we impose an increase in the moisture content of the atmosphere, and the dry static stability increases significantly in the midlatitudes, as predicted in Eq. (2). The moist theory of Eq. (2) predicts an increase in dry stability with moisture content and thus with the mean temperature of the atmosphere. Therefore one would expect increases in the static stability of the atmosphere in simulations of global warming if the meridional gradients do not change much. This can indeed be seen in the simulations of global warming from the Intergovernmental Panel on Climate Change Fourth Assessment Report archive, with significant increases in midlatitude stability occurring in every hemisphere season with the primary exception being Northern Hemisphere winter (Frierson 2006). In the Frierson (2006) study, the increases in stability are compared with changes in the meridional gradients, as in Eq. (2), and the primary differences from the theory are attributed to the effect of land.

The presence of land provides at least two additional complications to the static stability in the global warming simulations: in Northern Hemisphere summer, the increases in temperature over land in the global warming simulations significantly outpace the changes over ocean. Further, there is also limited availability of moisture over land, which causes moist convection to be less dominant. To better understand the determination of the static stability of the midlatitudes, we therefore find it useful to consider experiments with general circulation models over an aquaplanet surface, to eliminate the complications that the surface causes. We then hope to address the effect of an idealized land surface on static stability in a future study.

We use zonally symmetric, fixed sea surface temperature (SST) boundary conditions, varying the mean temperature and pole-to-equator temperature gradient separately. This separation into mean temperature and temperature gradient effects is useful in distinguishing between the theories of Eqs. (1) and (2). While the dry baroclinic eddy theories would not be expected to give changes in dry stability with mean temperature, the moist theory predicts a large increase in the dry stability over warmer temperatures due to increased moisture content.

This paper is organized as follows: a description of the models used and their boundary conditions are provided in section 2 . Then, in section 3 the static stability within the idealized GCM is studied, and in section 4 the full GCM simulations are examined. Section 5 concludes the paper.

\section{Description of model simulations}

\section{a. Sea surface temperature distributions}

The boundary conditions used in the simulations are from the paper by Caballero and Langen (2005). The surface is an aquaplanet (ocean-covered earth) with no topography, and fixed, zonally symmetric SST distributions. The SST distributions take the following functional forms, with two control parameters:

$$
T_{s}(\phi)=T_{m}-\Delta T\left(3 \sin ^{2} \phi-1\right) / 3,
$$

where $T_{m}$ is the global mean temperature, $\Delta T$ is the equator-pole temperature difference, and $\phi$ is latitude. The original Caballero and Langen (2005) full GCM simulations, which we analyze here as well, varied $T_{m}$ between $0^{\circ}$ and $35^{\circ} \mathrm{C}$ with $5-\mathrm{K}$ increments, and varied $\Delta T$ between 10 and $60 \mathrm{~K}$, with $5-\mathrm{K}$ increments. Simulations with surface temperatures above $45^{\circ} \mathrm{C}$ at the equator are omitted, due to uncertainties that the model physics can accurately simulate such warm climates. This gives a total of 69 full GCM simulations, which we analyze here. To save computational expense in the idealized model simulations, we run only a subset of these simulations with the idealized GCM, using $T_{m}$ values of $0^{\circ}, 10^{\circ}, 20^{\circ}, 30^{\circ}$, and $35^{\circ} \mathrm{C}$ only, and varying 
(a)

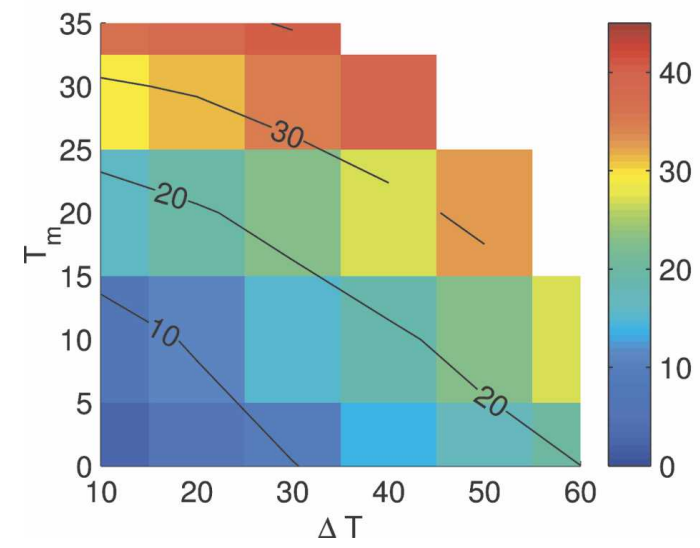

(b)

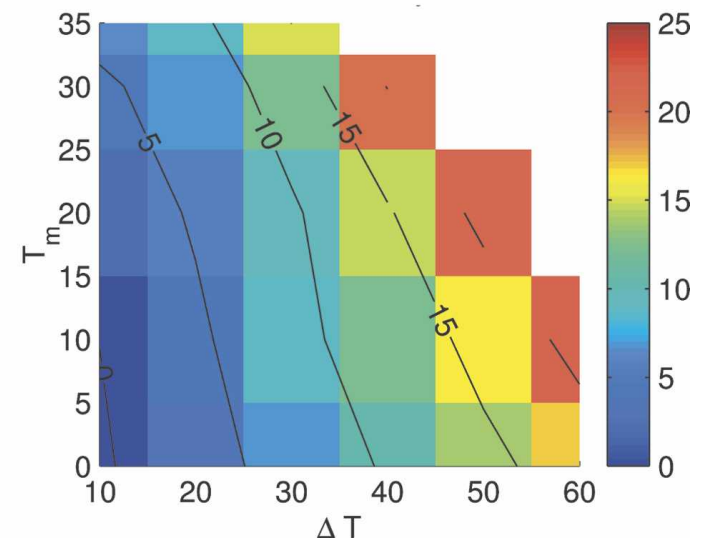

FIG. 1. (a) Bulk dry stability (K) and (b) bulk moist stability (K) between the surface and $400 \mathrm{hPa}$, averaged between $30^{\circ}$ and $60^{\circ}$ latitude, for the idealized GCM. See text for full definition of stabilities.

$\Delta T$ between 10 and $60 \mathrm{~K}$, with $10-\mathrm{K}$ increments. There are therefore a total of 24 idealized GCM experiments, nearly a factor of 3 less than the full GCM simulations. We found it unnecessary to run over the full suite of SSTs with the idealized model because the scaling relations were more clearly distinguishable in this model.

\section{b. Idealized moist general circulation model}

The idealized general circulation model consists of various simplified physical parameterizations coupled to a spectral dynamical core that solves the primitive equations. The physics includes gray radiative transfer, which means that water vapor and other constituents have no effect on radiative fluxes, a simplified MoninObukhov surface flux scheme, and a $K$-profile boundary layer scheme. These schemes are described in detail in Frierson et al. (2006), and all of the same parameters from the control simulation of this study are used. We additionally use a simplified Betts-Miller convection scheme (Betts 1986; Betts and Miller 1986), which is described in detail in Frierson (2007). The convection scheme is used to improve numerical convergence primarily in the tropics at the lower resolution than that used in the Frierson et al. (2006) simulations. The convection scheme parameters are $\tau_{\mathrm{SBM}}=2 \mathrm{~h}$ and $\mathrm{RH}_{\mathrm{SBM}}=0.8$, and the "shallower" shallow convection scheme from Frierson (2007) is chosen. The idealized GCM is run at T42 resolution, with 25 vertical levels. The simulations are spun up for $1 \mathrm{yr}$, and statistics are calculated over 3 subsequent years of integration.

\section{c. Full general circulation model}

The full GCM simulations were originally used to study poleward heat transports in the study of Cabal- lero and Langen (2005). The model is a comprehensive GCM, with realistic parameterizations of clouds, radiation, convection, and other physics. The atmospheric model used for these simulations is PCCM3, which is the atmospheric component of the Fast OceanAtmosphere Model (FOAM; Jacob 1997). The model uses the physical parameterizations of the National Center for Atmospheric Research (NCAR) Community Climate Model, version 3.6 (CCM3.6; Kiehl et al. 1996) and the dynamical core of the NCAR Community Climate Model, version 2 (CCM2). The full GCM is run at T42 resolution, with 18 vertical levels. These simulations are also spun up for $1 \mathrm{yr}$, and then statistics are taken for 3 subsequent years of simulation. When the SST is below $0^{\circ} \mathrm{C}$ in the full GCM, sea ice is specified.

\section{Static stability in the idealized GCM simulations}

We examine the midlatitude static stability first within the idealized GCM. In this section we first study simple measures of the midlatitude stability, with fixed averaging regions. We then refine the averaging regions to be more appropriate to the regions that are influenced by baroclinic eddies.

We begin by examining the static stability of the midlatitudes using a naive measure: we average over the midlatitudes, from $30^{\circ}$ to $60^{\circ}$ latitude, and examine bulk measures of the stability, differenced between the surface to $400 \mathrm{hPa}$. This is the same stability measure studied in Frierson (2006). The dry stability, that is, the difference in potential temperature between $400 \mathrm{hPa}$ and the lowest model level, is plotted in Fig. 1a for each of the 24 idealized GCM simulations. The $x$ axis of this plot is the meridional temperature gradient parameter 
(a)

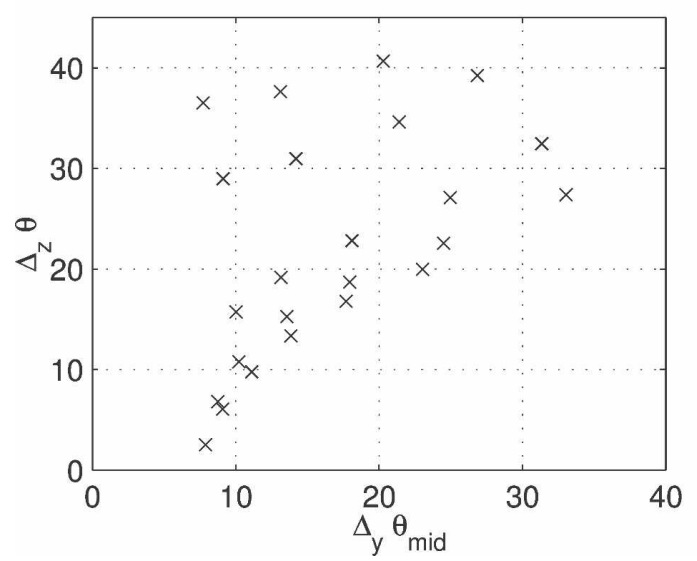

(b)

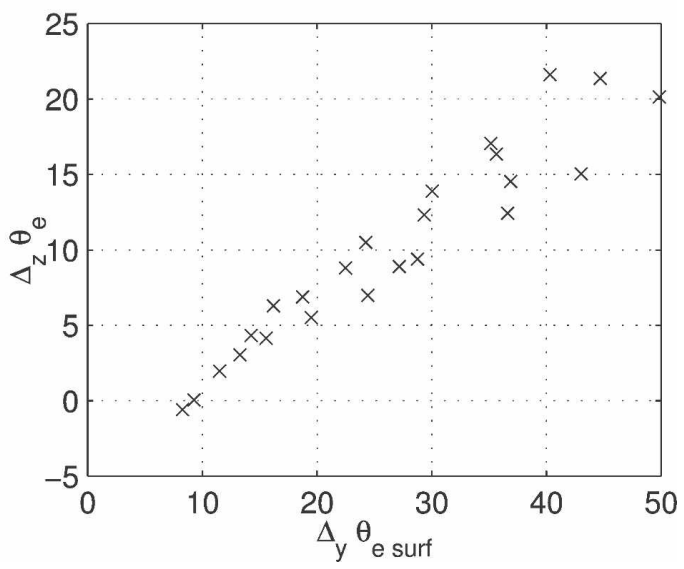

FIG. 2. Bulk stability (up to $400 \mathrm{hPa}$ ) vs meridional gradients, averaged between $30^{\circ}$ and $60^{\circ}$ latitude, for the idealized GCM. (a) Dry stability vs midtropospheric potential temperature gradient. (b) Moist stability vs surface equivalent potential temperature gradient.

$\Delta T$, and the $y$ axis is the mean temperature parameter $T_{m}$. Each rectangle in the plot represents one simulation. It is clear from this figure that the dry static stability varies considerably over the simulations we consider, from below $5 \mathrm{~K}$ to above $40 \mathrm{~K}$. The stability increases with meridional temperature gradient (e.g., from 15 to $35 \mathrm{~K}$ as $\Delta T$ varies from 10 to $60 \mathrm{~K}$ with $T_{m}=20$ ), but also increases with the mean temperature (e.g., from 10 to $40 \mathrm{~K}$ as $T_{m}$ varies from $0^{\circ}$ to $35^{\circ} \mathrm{C}$ with $\Delta T=30)$. Increasing the mean temperature by a fixed amount is in general more effective in increasing the static stability than increasing the temperature gradient.

We examine the moist stability changes averaged over the same midlatitude region in Fig. 1b. The moist stability is defined to be the saturated equivalent potential temperature at $400 \mathrm{hPa}$ minus the surface equivalent potential temperature. This is the identical moist stability measure considered in Frierson (2006). The moist stability varies significantly less than the dry stability. The smallest values occur for the lowest gradient, coldest climate, which actually has a small moist instability over the midlatitudes up to this height. The largest moist stabilities exist in the warmer simulations with the largest gradients. For instance, a moist stability of over $22 \mathrm{~K}$ is found for the $T_{m}=10^{\circ} \mathrm{C}, \Delta T=60 \mathrm{~K}$ case. The moist stability increases with increasing $\Delta T$ at all mean temperatures, and increases a smaller amount with increases in $T_{m}$.

We compare these initial bulk stability measures with the scaling theories presented in the introduction in Fig. 2. We first test the dry baroclinic eddy hypothesis [Eq. (1)] by comparing the dry stabilities with the midtropospheric $(500 \mathrm{hPa})$ potential temperature gradients in
Fig. 2a. The meridional gradients are calculated by differencing over the same averaging region, $30^{\circ}$ to $60^{\circ}$. It is clear that many of the simulations differ substantially from the dry baroclinic eddy prediction, with significantly larger stabilities than predicted by the meridional gradients. These are the warmer simulations in Fig. 1 , which achieve their larger dry stabilities without a corresponding increase in meridional gradients. Only the coldest simulations exhibit any kind of linear scaling of stability with temperature gradients. The dry baroclinic eddy scaling of Schneider (2004), which uses surface meridional gradients instead of midtropospheric gradients, works worse than the baroclinic adjustment version tested in Fig. 2a (not shown).

In Fig. 2b, we compare with the moist theory of Juckes (2000), plotting the moist stability against the surface equivalent potential temperature gradient. These quantities exhibit a strong correlation: the simulations with larger moist stabilities in Fig. 1b are associated with larger surface equivalent potential temperature gradient. The surface equivalent potential gradient clearly increases with increases in $\Delta T$; however, this gradient can increase with $T_{m}$ as well, due to increases in moisture content. The slope implied by Fig. $2 b$ is approximately 0.5 , with a $2^{\circ}$ increase in meridional gradient leading to a $1-\mathrm{K}$ increase in moist stability. The primary discrepancy in the moist scaling theory is the intercept. The scaling relation does not go through the origin, and instead exhibits near-zero stability with finite meridional gradient. We address this point later in this section.

While it is useful to examine the stability over fixed averaging regions, as in Figs. 1-2, there are shifts in the 
(a)

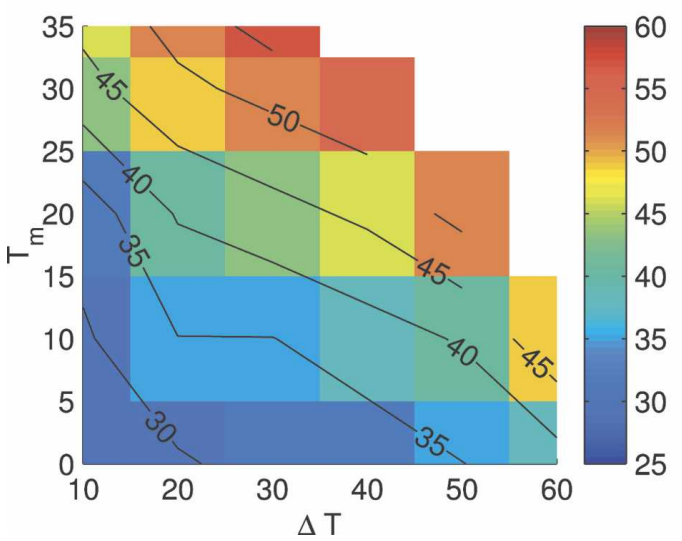

(b)

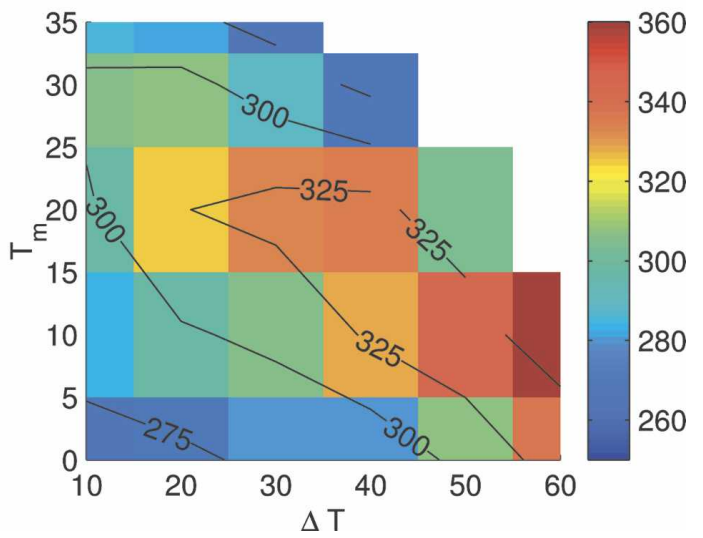

FIG. 3. (a) Latitude of maximum vertically integrated eddy kinetic energy $\left(^{\circ}\right.$ ) and (b) pressure of the tropopause $(\mathrm{hPa})$ for all idealized GCM simulations.

typical areas where baroclinic eddies occur in these simulations, which should be taken into account in the scaling theories. These shifts occur both in the horizontal and vertical. First, there are significant shifts in the latitudes where baroclinic eddy activity is occurring in the simulations, as can be seen from Fig. 3a, which plots the latitude of maximum eddy kinetic energy (EKE), vertically integrated from the surface to $100 \mathrm{hPa}$. Some of the simulations with the weakest temperature gradients $(\Delta T=10 \mathrm{~K})$ have maximum EKE at the equator; we take the secondary maximum in the midlatitudes as the latitude in these cases. One can see from Fig. 3a that there are large meridional shifts in EKE with both mean temperature and meridional temperature gradient. The latitude of maximum EKE shifts poleward both with increases in mean temperature and with meridional gradient. For example, the jet shifts from $32^{\circ}$ to $57^{\circ}$ as the mean temperature increases from $0^{\circ}$ to $35^{\circ} \mathrm{C}$ with $\Delta T=30 \mathrm{~K}$, and from $34^{\circ}$ to $50^{\circ}$ as $\Delta T$ varies from 10 to $50 \mathrm{~K}$ at $T_{m}=20^{\circ} \mathrm{C}$. The $\mathrm{GCM}$ exhibits a poleward shift of approximately $0.7^{\circ}$ per $1 \mathrm{~K}$ increase in $T_{m}$. The shift with meridional temperature gradient is smaller than this in general. We later show that the full GCM has a significantly different response in terms of sensitivity to meridional gradients, but exhibits a similar sensitivity to mean temperature.

A poleward shift of the jet has been seen in observations over recent decades (Fu et al. 2006), simulations of global warming (Yin 2005), and has been noted in the simulations of Frierson et al. (2007a) using this same model as a response to increased moisture content. The poleward shift of the jet stream is often associated with a shift of the Hadley circulation edge (Lu et al. 2007), which we study for these model simulations in Frierson et al. (2007b). All of these responses could be analogous to the shift with mean temperature seen here. We do not perform a thorough investigation of possible mechanisms for the shift of EKE in these simulations: some mechanisms that have been proposed include changes in meridional temperature gradients (Frierson et al. 2007a; Yin 2005), changes in static stability ( $\mathrm{Lu}$ et al. 2007), changes in tropopause height (Lorenz and DeWeaver 2007), stratospheric dynamics (Polvani and Kushner 2002), and changes in eddy momentum flux spectra (Chen et al. 2007).

In addition to latitudinal shifts, there are also can be vertical shifts of eddy activity. This is not a dominant factor in the idealized GCM simulations, but is of fundamental importance for the full GCM, so we present the changes in tropopause height here for completeness. The pressure of the tropopause, taken as the level where the lapse rate first hits $4 \mathrm{~K} \mathrm{~km}^{-1}$ and averaged in a $25^{\circ}$ band around the latitude of maximum EKE, is plotted in Fig. 3b. We use the slightly unorthodox definition of the tropopause (using $4 \mathrm{~K} \mathrm{~km}^{-1}$ instead of $2 \mathrm{~K}$ $\mathrm{km}^{-1}$ ) because the latter criterion produces somewhat unusual bulk stability profiles. For instance, the moist stability can be largest at the equator (despite essentially moist adiabatic profiles up to a slightly lower depth), and then decrease out to the poles. The $4 \mathrm{~K}$ $\mathrm{km}^{-1}$ criterion appears to be more suitable for measuring bulk stabilities, and for capturing the movement of eddy kinetic energy in the vertical over the wide parameter range studied here. We discuss sensitivities to this criterion when appropriate. The tropopause using this definition is around $300 \mathrm{hPa}$ in all cases for the idealized GCM. In general, the tropopause lowers with both increases in mean temperature and increases in temperature gradient, but there is nonuniform behavior in several areas of the plot. 
(a)

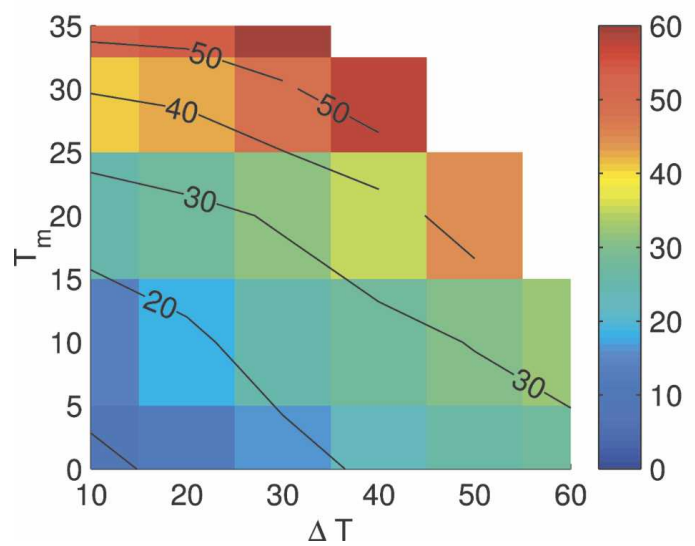

(b)

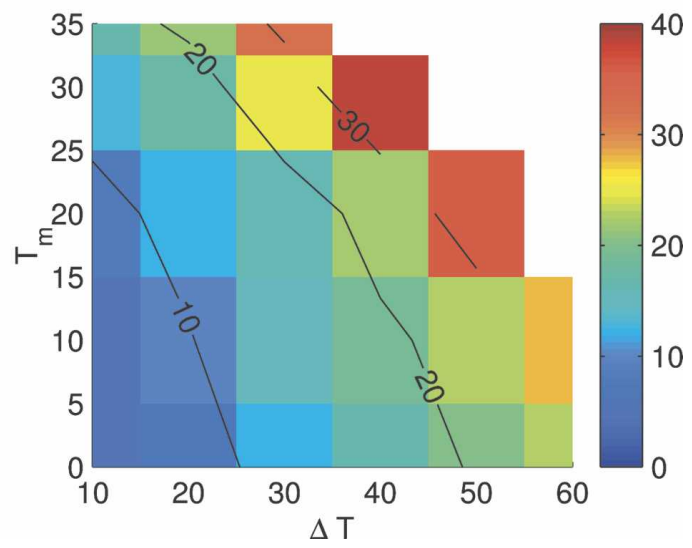

FIG. 4. (a) Bulk dry stability (K) and (b) bulk moist stability (K) between the surface and the tropopause, averaged within $25^{\circ}$ of the latitude of maximum eddy kinetic energy for the idealized GCM. See text for full definition of stabilities.

We design a new stability measure taking the above two shifts into account. We average meridionally over a $25^{\circ}$ region (nine grid points) centered around the EKE maximum, and calculate stabilities up to the tropopause height. The new stability measure is more appropriate for the actual regions that are affected by baroclinic eddies. We plot the dry stability and moist stability using the new measure in Fig. 4. The primary difference in these measures is that the new moist stability increases more with mean temperature as well as temperature gradient. The dry stabilities now range from just under $10 \mathrm{~K}$ for the coldest, lowest gradient case to almost 60 $\mathrm{K}$ for the warmest cases. The moist stabilities range from 5 to nearly $40 \mathrm{~K}$.

(a)

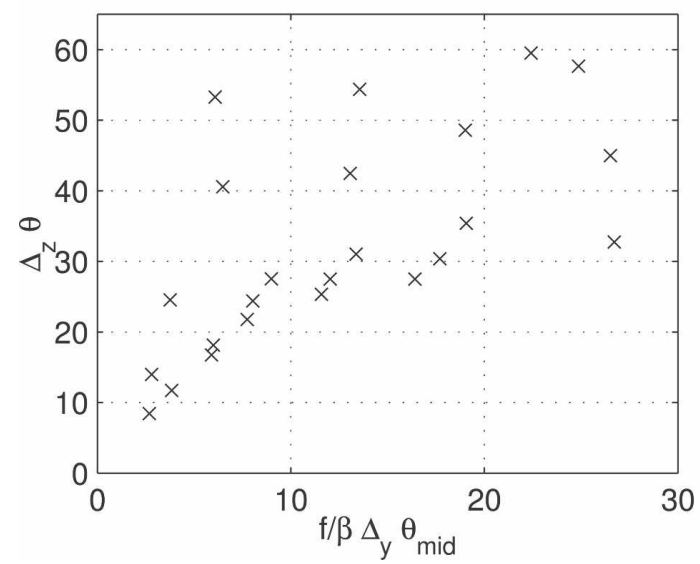

We examine the theories of Eqs. (1) and (2) again with the more appropriate averaging regions selected for all cases in Fig. 5. In calculating the dry baroclinic scaling in Fig. 5a, we multiply the midtropospheric temperature gradient by a factor proportional to $f / \beta$ calculated at the latitude of maximum EKE; that is, we multiply by $\tan \phi$ with $\phi$ the latitude of maximum EKE. The use of the $f / \beta$ factor significantly improves agreement with the dry theory in all cases. Examining Fig. 5a, we find that the dry baroclinic adjustment hypothesis still does not do well in capturing the behavior of the static stability. The warmest simulations exhibit a large increase in static stability that is not a function of midtropospheric temperature gradient. However, even ignor-

(b)

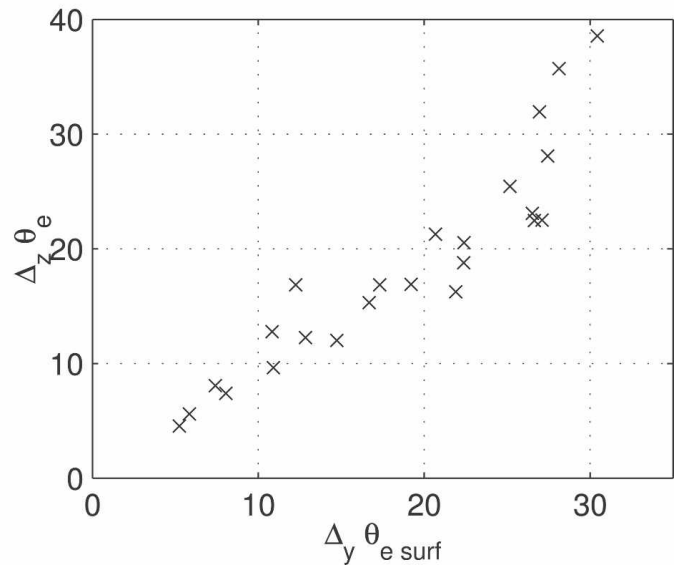

FIG. 5. Bulk stability (up to tropopause) vs meridional gradients, averaged $25^{\circ}$ around the latitude of maximum eddy kinetic energy. (a) Dry stability vs midtropospheric potential temperature gradient times $f / \beta$. (b) Moist stability vs surface equivalent potential temperature gradient. 
(a)

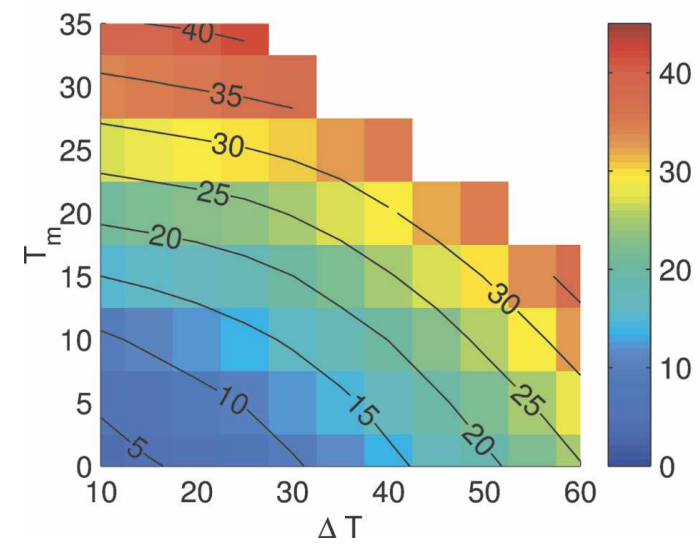

(b)

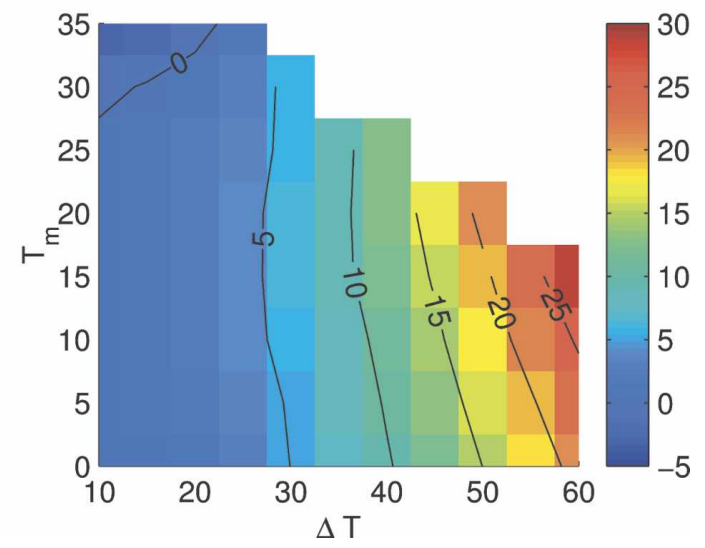

FIG. 6. (a) Bulk dry stability (K) and (b) bulk moist stability (K) between the surface and $400 \mathrm{hPa}$, averaged between $30^{\circ}$ and $60^{\circ}$ latitude for the full GCM simulations. See text for full definition of stabilities.

ing the warmest and highest temperature gradient cases does not give a better agreement with the dry scaling theory. Again using surface temperature gradients as in Schneider (2004) worsens the agreement in Fig. 5a, shifting the higher-stability points on the curve to the left (not shown).

Examining the moist theory of midlatitude static stability in Fig. 5b shows excellent agreement. All of the simulations lie on a line whose slope is slightly greater than one that intercepts the origin. The use of the different averaging regions has now solved the problem of nonzero intercept that was found in Fig. 2. There is a slight tendency toward an upward shift in the warmest, highest gradient cases, but the agreement is quite good in general. Figure 5 gives strong support for the theory of Juckes (2000) and Frierson et al. (2006), and indicates that moisture is controlling the temperature structure of midlatitudes in a relatively simple manner in this idealized aquaplanet model. The discrepancies in Fig. $5 \mathrm{~b}$ are possibly due to either arbitrariness in definition of the tropopause, or to changes in surface mixing lengths, which would cause the surface standard deviation of equivalent potential temperature to be not simply proportional to its gradient. With the dry theory clearly ruled out and strong support for the moist theory in the idealized GCM, we move on to studying the full GCM to see if similar mechanisms are at work in determining the midlatitude static stability in that context.

\section{Static stability in the full GCM simulations}

We next examine the static stability in the full GCM using the fixed measure, averaged between $30^{\circ}$ and $60^{\circ}$ latitude and between the lowest model level and 400 $\mathrm{hPa}$. The dry stabilities for the 69 full GCM simulations are plotted in Fig. 6a. This figure shows a similar behavior in dry static stability as in the idealized GCM. Again the dry stability varies considerably over the simulations we consider, from below $5 \mathrm{~K}$ for the cold, low gradient climates, up to above $40 \mathrm{~K}$ for the warmest climates. The stability increases with meridional temperature gradient (e.g., from 15 to $36 \mathrm{~K}$ as $\Delta T$ varies from 10 to $60 \mathrm{~K}$ with $T_{m}=15$ ), but also increases with the mean temperature (e.g., from 10 to $36 \mathrm{~K}$ as $T_{m}$ varies from $0^{\circ}$ to $30^{\circ} \mathrm{C}$ with $\Delta T=30$ ). In general, the stabilities in the full GCM are slightly larger than idealized GCM at most points.

We examine the moist stability changes averaged over the same fixed midlatitude region in Fig. 6b. Similarly to the idealized model, the moist stability exhibits an increase with increasing meridional gradient. However, with mean temperature gradient increases, the moist stability stays much more constant with height. The smallest values now occur for the lowest gradient, warmest climates, which have a small moist instability over the midlatitudes up to $400 \mathrm{hPa}$. The largest moist stabilities exist in the warmest simulations with $\Delta T=60$ $\mathrm{K}$, with a moist stability of $28 \mathrm{~K}$ for the $T_{m}=15^{\circ} \mathrm{C}$, $\Delta T=60 \mathrm{~K}$ case. It is interesting to note that some of the full GCM simulations exhibit smaller moist stabilities despite larger dry stabilities. This is due to the larger surface relative humidities in the full GCM as compared to the idealized GCM.

We compare the fixed bulk stability measures with the scaling theories for the full GCM in Fig. 7. We test the dry baroclinic eddy theory in Fig. 7a, which is analogous to the test performed for the idealized model in Fig. 2a. Here again the high $T_{m}$ simulations differ substantially from the dry baroclinic eddy prediction, with much larger stabilities than predicted by the meridional 
(a)

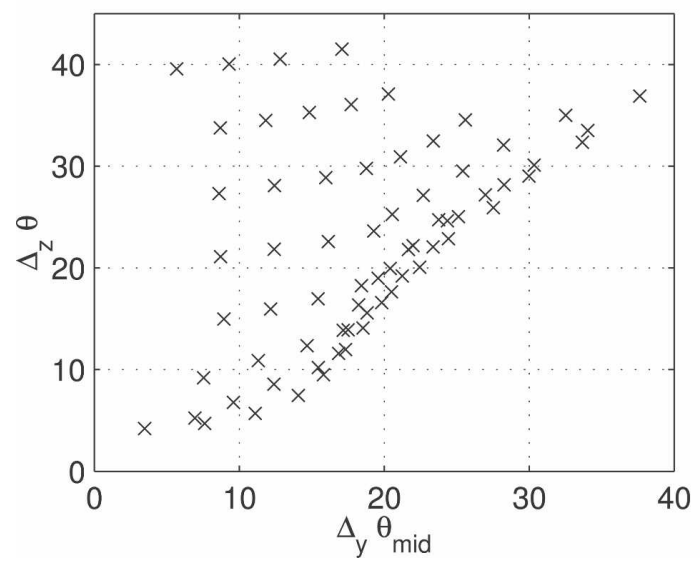

(b)

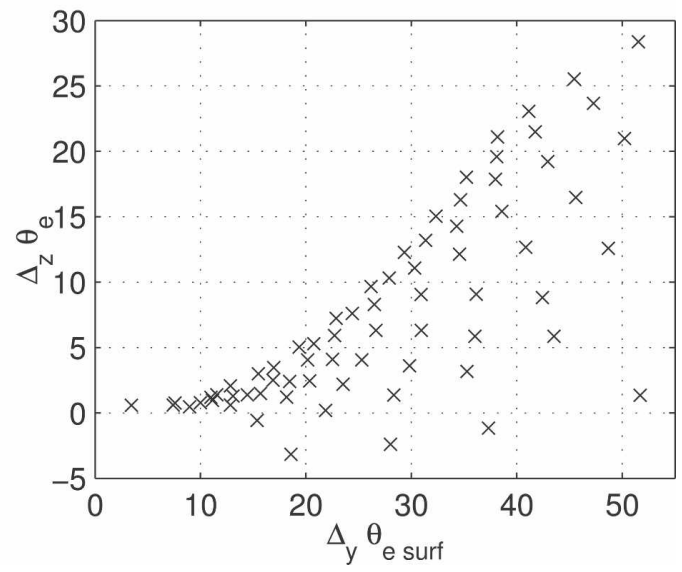

FIG. 7. Bulk stability (up to $400 \mathrm{hPa}$ ) vs meridional gradients, averaged between $30^{\circ}$ and $60^{\circ}$ latitude for the full GCM simulations. (a) Dry stability vs midtropospheric potential temperature gradient. (b) Moist stability vs surface equivalent potential temperature gradient.

gradients. However, there are some simulations in which the dry stability appears to approximately scale with the midtropospheric temperature gradient. These are the colder, higher gradient climates that we consider. We study whether the static stability in these cases can actually be considered to be set by dry baroclinic eddy dynamics in more detail later in the paper. The Schneider (2004) theory using surface meridional gradients does not exhibit such a clustering of the coldest simulations along a line, and performs worse for all cases (not shown).

In Fig. 7b, we compare with the moist convective theory of Eq. (2), plotting the moist stability against the surface equivalent potential temperature gradient. Here there is also a significant difference from the ide- alized model. The moist stability and the surface meridional gradient are correlated in general, but there is a significant amount of spread in these simulations, with many simulations having moist stabilities lower than the line defined by the coldest simulations. One may infer from these plots that convection is playing some role in the determination of the static stability in the full GCM, but is not the sole determinant. However, we next show this conclusion to be incorrect by examining the shifts in latitude and in height, and examining the more appropriate stability measure. We find that the shifts are different in the full GCM, but the determination of the static stability is likely similar.

First, we plot the latitude of maximum EKE, integrated between the surface and $100 \mathrm{hPa}$ in Fig. 8a. As in (a)

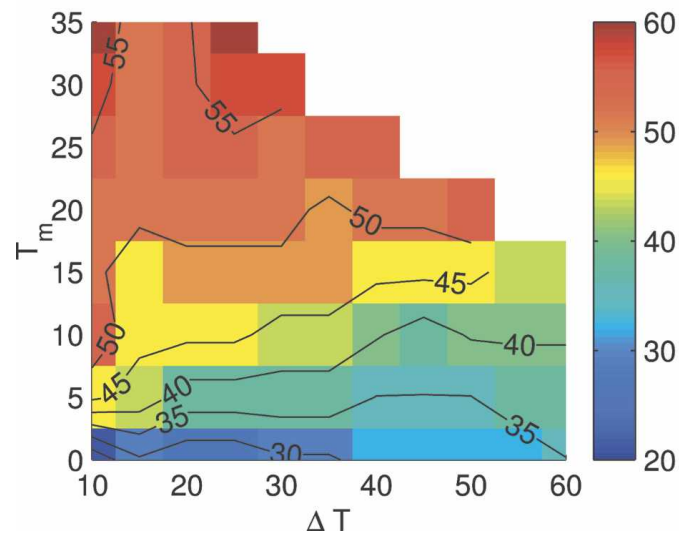

(b)

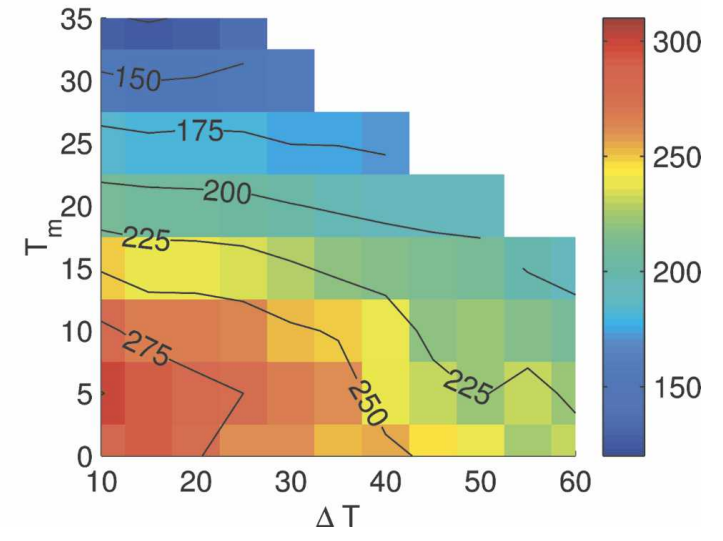

FIG. 8. (a) Latitude of maximum eddy kinetic energy $\left({ }^{\circ}\right)$ and (b) pressure of the tropopause (hPa) for the full GCM simulations. 
the idealized GCM, there is a large poleward shift of EKE as the mean temperatures increase. However, the poleward shift with increasing temperature gradient seen in Fig. 3a is not seen in this model. The jet shift in this model is primarily a function of mean temperature only. It is difficult to assign an average shift per degree warming in Fig. 8a, because the shift is more nonuniform in this model. Much of the shift occurs for colder temperatures, with $T_{m}$ between $0^{\circ}$ and $15^{\circ} \mathrm{C}$. The idealized model and the full GCM also differ significantly in jet location for many of the simulations. While a few of the high gradient cases have the jet latitude of the full GCM located equatorward of the idealized model's jet, for the most part the full GCM is shifted poleward with respect to the idealized GCM. It is important at some point to understand these differences to develop a better understanding of the jet location in general, and the usefulness of idealized models to study this question. We do not address these concerns in detail here, as the explanations are likely not simple. However, one aspect that may be causing some of the differences between these models is the tropopause height, which we examine next and has been shown to be important in determining the jet latitude in idealized model studies (Williams 2006; Lorenz and DeWeaver 2007).

While in the idealized GCM, the tropopause height stays relatively fixed, there are large changes in this quantity in the full GCM, as can be seen in Fig. 8b. The tropopause height exhibits a large increase with mean temperature, and increases with meridional gradient to a lesser extent as well. The tropopause is above $300 \mathrm{hPa}$ in the coldest, lowest gradient cases. The highest tropopauses occur in the cases with mean temperature of $35^{\circ} \mathrm{C}$, where the tropopause height is between 100 and $150 \mathrm{hPa}$. The heights seen in Fig. $8 \mathrm{~b}$ are representative of the typical upper tropospheric maxima of eddy kinetic energy for all cases: the eddies shift upward with mean temperature as well.

It is generally expected that a warmer troposphere would lead to a higher tropopause height: with a fixed tropopause temperature and a constant lapse rate, the tropopause height increases with surface temperature. Further, a decreased lapse rate with increased mean temperature (Fig. 6a) adds to this effect and causes the tropopause to rise more. The lapse rate effect is likely dominant in causing the mild increase in tropopause height with meridional temperature in Fig. 8b. Increases in tropopause height have also been seen in observations over recent decades (Santer et al. 2003; Seidel and Randel 2006) and in simulations of global warming (Santer et al. 2003).

So if the increase in tropopause height with increas- ing mean temperature and decreasing lapse rate is expected, why does this not occur for the idealized GCM? The answer is that the tropopause temperature is not as constrained in this model. With gray radiative transfer, and no constraint on the outgoing longwave radiation/ skin temperature, the tropopause temperature varies considerably in the idealized model simulations, which allows the invariance of tropopause height in Fig. 3b. In fact, in gray radiative-convective equilibrium with a fixed lapse rate, one can show analytically that the tropopause temperature adjusts so that the pressure of the tropopause is completely insensitive to the surface temperature. It is also worth discussing the reasons that the tropopause height is lower in general for the idealized GCM. Preferential depletion of frequency bands (e.g., $\mathrm{CO}_{2}$ bands) in the lower atmosphere allows the tropopause area to cool efficiently by emitting in those same bands. In the gray model, there is no frequency dependence of absorption or emission, so such enhanced cooling cannot occur. Thus with a full radiative transfer scheme, the tropopause temperature is significantly lower, and the tropopause is higher (R. Pierrehumbert 2006, personal communication).

We next study the stability measure that takes into account the shifts in latitude and tropopause height. We again average meridionally over a $25^{\circ}$ region (nine grid points) centered around the EKE maximum, and calculate stabilities up to the tropopause height. We plot the dry stability and moist stability using the new measure in Fig. 9. Dry and moist stability both increase for all simulations using this measure, which is not surprising because the tropopause height is well above $400 \mathrm{hPa}$ for all cases. Now the dry stabilities range from $15 \mathrm{~K}$ for the coldest, lowest gradient case to $70 \mathrm{~K}$ for the warmest cases. The moist stabilities exhibit more of a qualitative change. The new moist stability increases with mean temperature as well as temperature gradient, as for the idealized GCM in Figs. 1b and $4 b$.

Examining the theories of Eqs. (1) and (2) again with the more appropriate averaging regions selected for all cases, we find that the dry baroclinic eddy hypotheses perform significantly better than in the idealized GCM simulations. The warmer cases still do not conform to the scaling relation, experiencing significantly larger stabilities than predicted by Eq. (1). It is fair to rule out baroclinic adjustment from occurring in any of the simulations with $T_{m}=20^{\circ}-35^{\circ} \mathrm{C}$. In the colder simulations, however, it is impossible to discount the baroclinic adjustment hypothesis. A regime transition between convectively controlled and eddy-controlled stability occurs in simulations of Schneider and Walker (2006). We examine these simulations in more detail later in the paper, to see whether a regime transition is 
(a)

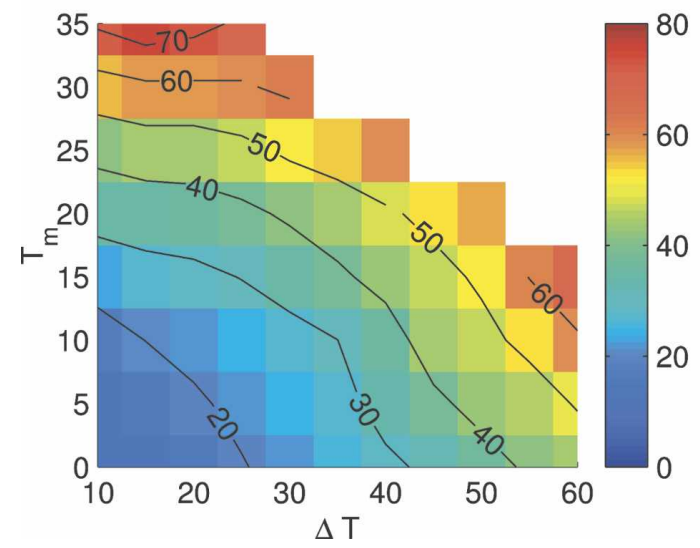

(b)

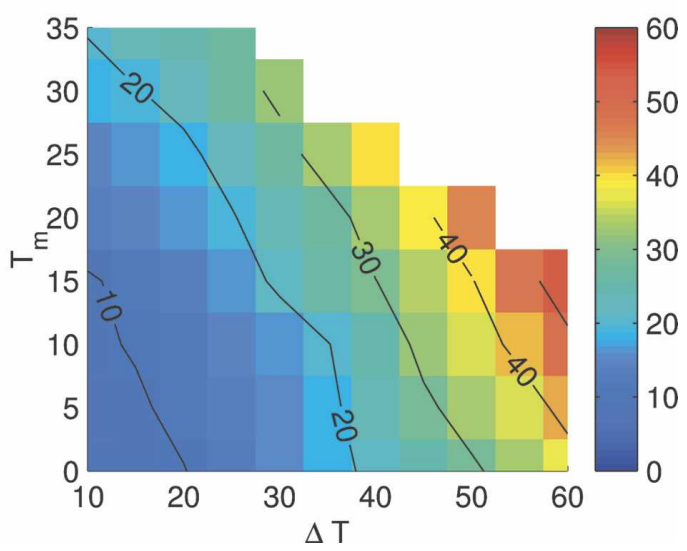

FIG. 9. (a) Bulk dry stability (K) and (b) bulk moist stability (K) between the surface and the tropopause, averaged within $25^{\circ}$ of the latitude of maximum eddy kinetic energy for the full GCM simulations. See text for full definition of stabilities.

the proper way to interpret these simulations. It is important to note that the poleward shift of the jet and the factor of $f / \beta$ is a very important factor in improving the agreement in Fig. 10a. The increase in latitude of maximum EKE allows larger static stabilities without increased meridional gradients, by increasing $f$ and decreasing $\beta$ in Eq. (1). We additionally plot the Schneider (2004) scaling theory for these quantities in Fig. 11. This theory does similarly well to the baroclinic adjustment formulation in this case, with large deviations occurring for the high temperature cases, and a fairly linear scaling for the colder simulations. In the Schneider (2004) framework, again both the poleward shift of the jet and the $f / \beta$ factor are important in improving the agreement in the colder cases.

(a)

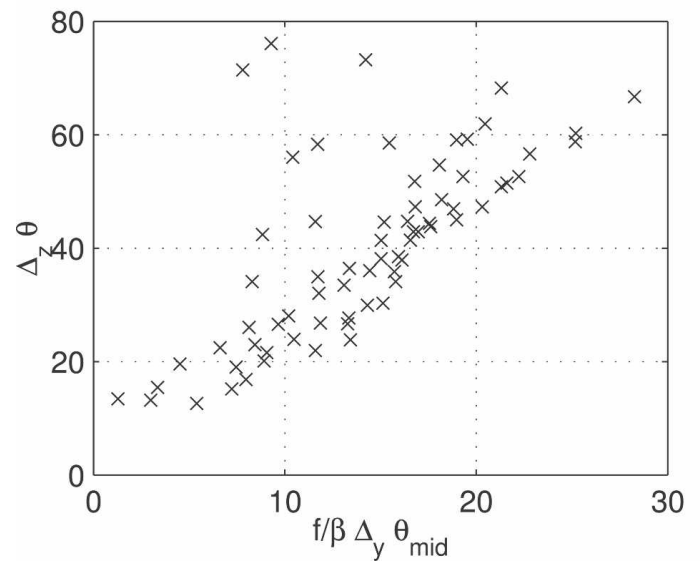

We next examine the moist theory of midlatitude static stability in Fig. 10b. The theory of Eq. (2) shows excellent agreement for all simulations, now that the two shifts in circulation are taken into account. As in Fig. 5b, all of the simulations here lie on a line whose slope is slightly greater than one that intercepts the origin. Changes in tropopause height are most important in improving the scaling relation from Fig. 7b, but changes in the latitudes also contribute. It is somewhat remarkable that while the dry theory shows agreement only in a certain range of simulations, the moist theory shows no such disagreement over any parameter regime. As in the idealized GCM, wherever the surface equivalent potential temperature gradients are larger, the moist stability increases in an approximately linear

(b)

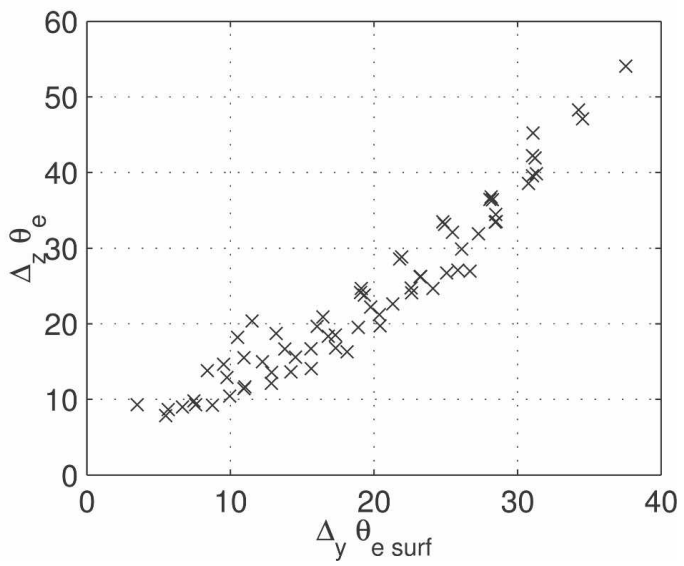

FIG. 10. Bulk stability (up to tropopause) vs meridional gradients, averaged $25^{\circ}$ around the latitude of maximum eddy kinetic energy for the full GCM simulations. (a) Dry stability vs midtropospheric potential temperature gradient times $f / \beta$. (b) Moist stability vs surface equivalent potential temperature gradient. 


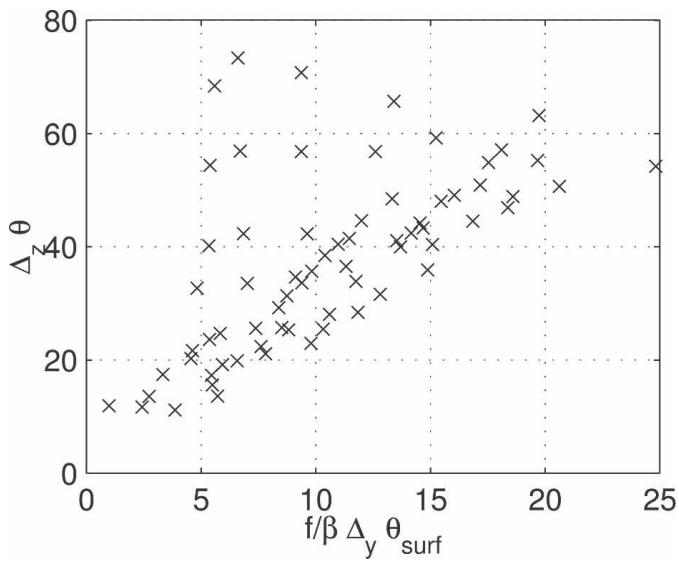

FIG. 11. Dry baroclinic scaling theory of Schneider (2004): bulk stability (up to tropopause) vs surface meridional potential temperature gradient, averaged $25^{\circ}$ around the latitude of maximum eddy kinetic energy for the full GCM simulations.

manner as well. There is a slight tendency in Fig. 10b toward increased stability relative to the linear fit at higher temperature gradients, as in the idealized model. We again suggest that possible reasons for this behavior are the arbitrariness of tropopause height selection, or changes in surface mixing length.

In section 3, we describe the slightly unorthodox tropopause definition that we use here. If the standard WMO criterion is used in Fig. 10, both the dry and moist theories are made worse, essentially by shifting both of these curves upward. The dry theories are made slightly worse than the moist theory with the WMO tropopause. Changing the tropopause criteria we use by a degree in either direction (e.g., to 3 or $5 \mathrm{~K} \mathrm{~km}^{-1}$ ) does not qualitatively change the results we present here. We have also experimented with different averaging regions around the EKE maximum, which also does not qualitatively change the results by a significant amount.

To better study whether the dry and moist theories can be distinguished in the colder temperature cases, we directly compare these scalings for mean temperatures of $0^{\circ}-15^{\circ} \mathrm{C}$ only in Fig. 12. Both the dry baroclinic adjustment scaling theory (Fig. 12a) and the moist scaling theory (Fig. 12c) show approximately equivalent agreement, with the Schneider (2004) theory (Fig. 12b) working slightly less well. The primary difference in the dry baroclinic adjustment scaling theory in Fig. 12a are large spreads of over $10 \mathrm{~K}$ with the middle temperature gradients, and large stabilities for the coldest, lowest gradient cases. In the moist scaling in Fig. 12c, the primary differences are spreads of approximately $7 \mathrm{~K}$ over the middle $\Delta_{y} \theta_{e \text { surf }}$ values, and the general tendency toward upward concavity. Since the dry scaling theories do not perform better in any regime of the simulations considered here, we argue that the most parsimonious explanation is that moisture controls the static stability in the full GCM for all simulations, as it does in the idealized GCM. An additional comforting result about the moist scaling theory is that this provides a very simple explanation for why the dry static stability increases with mean temperatures: that the moist adiabat is more stable with increased surface temperatures. The explanation involving Eq. (1) would have to reference (a)

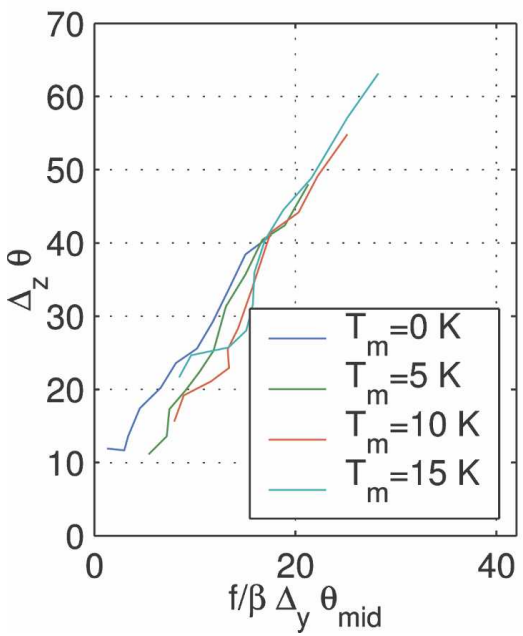

(b)

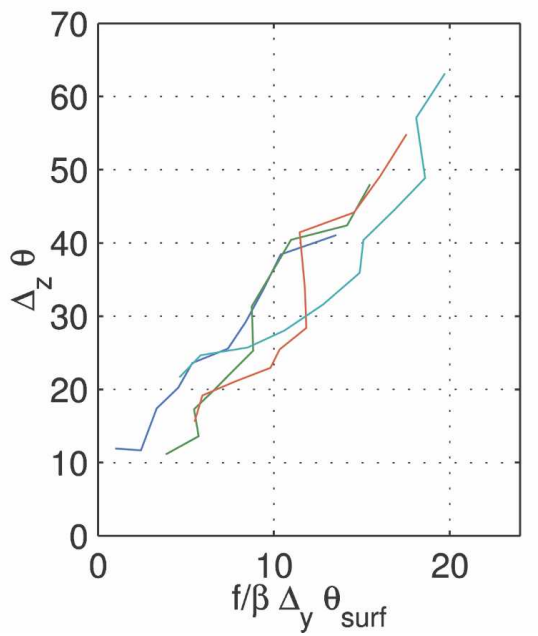

(c)

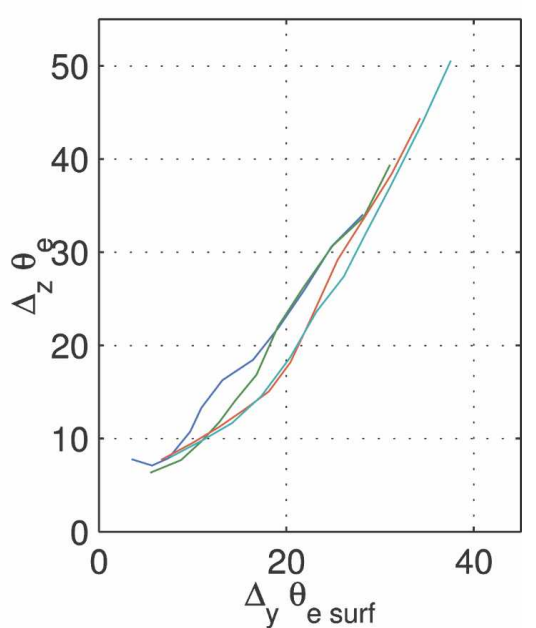

FIG. 12. Bulk stability (up to tropopause) vs meridional gradients, averaged $25^{\circ}$ around the latitude of maximum eddy kinetic energy, for only the coldest mean temperature full GCM simulations, with $T_{m}=0,5^{\circ}, 10^{\circ}$, and $15^{\circ} \mathrm{C}$. Each line connects the simulations with fixed $T_{m}$. (a) Dry stability vs midtropospheric potential temperature gradient times $f / \beta$. (b) Dry stability vs surface potential temperature gradient times $f / \beta$. (c) Moist stability vs surface equivalent potential temperature gradient. 
(a)

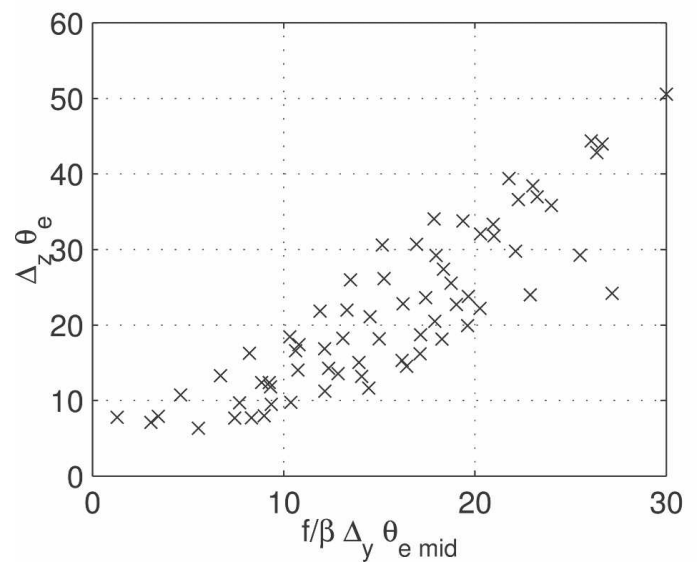

(b)

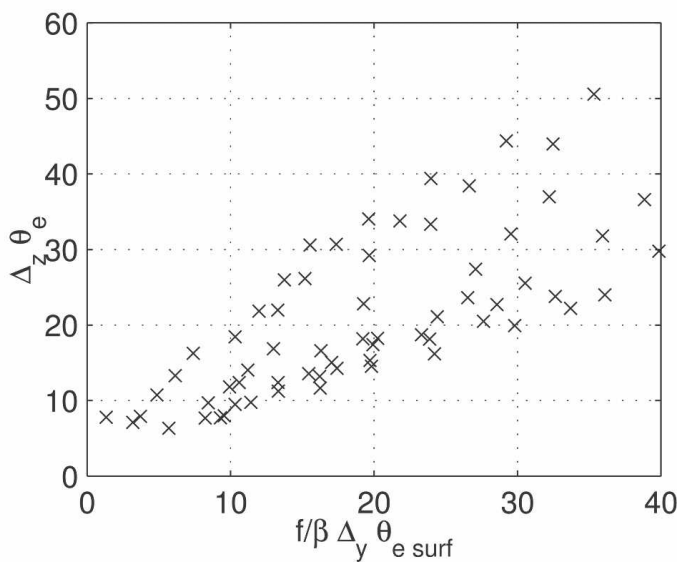

FIG. 13. Alternative moist scaling theories for the full GCM simulations. (a) Moist stability vs midtropospheric equivalent potential temperature gradient times $f / \beta$. (b) Moist stability vs surface equivalent potential temperature gradient times $f / \beta$. All quantities are averaged up to the tropopause height and within $25^{\circ}$ of the latitude of maximum eddy kinetic energy.

the poleward shift of the jet and complicated changes in midtropospheric gradients that do not follow the surface temperature gradients. We find these results rather convincing for the relevance of moisture in determining the static stability of midlatitudes for all the simulations considered here. More simulations or diagnostics are necessary to fully evaluate the importance of dry baroclinic eddies versus moist processes in the colder full GCM cases, for instance, by examining where convection occurs within baroclinic eddies in these simulations, and examining vertical eddy dry static energy fluxes versus convective fluxes. Unfortunately such diagnostics are not available for the full GCM simulations (as only monthly averaged data exist), so additional simulations will be necessary to perform such diagnostics.

It is interesting to discuss the reasons why baroclinic adjustment theories may appear to be true if moisture actually controls the static stability. We believe the poleward shift of the jet with warmer temperatures is intimately related to this, for two reasons. The jet shifts strongly toward higher latitudes with increases in mean temperature, by up to $30^{\circ}$. This shift moves the eddy activity first of all toward colder temperatures, where there is less moisture. Second, it moves the jet toward larger values of $f / \beta$, so the stability can be larger for fixed meridional temperature gradients. It is likely that both of these factors contribute to give the degree of agreement seen in Fig. 10a. Since the full GCM has its jet latitude poleward of the idealized GCM for many of the cooler simulations, this additionally explains why the dry scaling works better in the full GCM than the idealized GCM.
A final question of interest is whether any alternative moist theories would be successful at predicting the midlatitude temperature structure. For instance, one may attempt to extend the dry baroclinic hypotheses to include moisture by simply replacing the potential temperature with equivalent potential temperature in Eq. (1). We note that this is heuristic in both the baroclinic adjustment viewpoint and the potential vorticity diffusion framework. It is inadequate in the baroclinic adjustment case because there is no clear baroclinic instability criterion for moist baroclinic instability. Further, it is impossible to define a moist potential vorticity quantity that is conserved in the presence of condensation, so diffusive scalings such as Schneider (2004) should not be expected to be easily extended to include moisture either.

However, despite these limitations, we have examined these alternative moist scalings for both GCMs. For the idealized GCM, it is impossible to distinguish between the theory presented in Eq. (2) and theories replacing the potential temperature with equivalent potential temperature in either the baroclinic adjustment framework or the diffusive framework. In the full GCM, on the other hand, it is possible to rule out both of the alternative moist scalings. These are plotted in Fig. 13. Figure 13a shows the moist version of the baroclinic adjustment theory, and Fig. 13b shows the moist version of the diffusive theory. It is clear from these plots that the alternative moist hypotheses are significantly less adequate than the scaling shown in Fig. $10 \mathrm{~b}$. This result is suggestive that the Juckes (2000) framework is the proper moist framework for thinking about midlatitude stability. However, we emphasize that the 
only definite conclusion that can be made without further study is that moisture plays a fundamental role in setting the midlatitude static stability. In particular, more research is needed to determine whether moist convection within baroclinic eddies does indeed play the fundamental role in setting the midlatitude stability, or whether some nonconvective moisture effects on baroclinic eddies are sufficient.

\section{Conclusions}

We have studied the determination of the midlatitude static stability in two aquaplanet general circulation models. Our studies of coupled atmosphere-ocean model simulations have indicated that land surfaces complicate the determination of the static stability in midlatitudes in the Northern Hemisphere (Frierson 2006), so the aquaplanet framework is a useful one for evaluating the efficacy of simple theories for midlatitude stability. Further, the use of the set of fixed SST boundary conditions studied by Caballero and Langen (2005) additionally simplifies the interpretation of results. A zonally symmetric surface allows us to ignore such complications as stationary waves, while the simplification into changes due to mean temperature and temperature gradient is a useful simplification as well.

We study the stability in an idealized GCM, with highly simplified physical parameterizations, and a full GCM, with state-of-the-art parameterizations of radiative transfer, clouds, convection, and other processes. The results from the idealized model are clear. There we find that "baroclinic adjustment," the conjecture that the dry isentropic slope should stay constant (Stone 1978), has no success in predicting the temperature structure of the atmosphere. There are large changes in the static stability that are not accompanied by changes in the meridional temperature gradient, meaning that the isentropic slope varies considerably. An alternative dry baroclinic eddy hypothesis based on potential vorticity diffusion (Schneider 2004) can also be clearly ruled out for these simulations.

In the idealized model, a moist scaling theory, similar to that originally proposed by Juckes (2000), modified slightly by Frierson et al. (2006), works quite well in predicting the static stability of the atmosphere over a wide parameter range. This theory postulates that the moist stability of the atmosphere is proportional to the equivalent potential temperature gradient at the surface. Therefore given the surface temperature gradient, one can calculate both the moist and dry stability to a high degree of accuracy. Increases in mean temperature increase the dry static stability both through increases in the dry stability of the moist adiabat, and through increases in the surface equivalent potential temperature and its gradient (which increases the moist stability as well as the dry stability).

In the full GCM, the moist scaling theory also works well, when vertical and meridional shifts of the circulation are taken into account. There are large upward shifts of the tropopause and poleward shifts of eddies as the mean temperature increases. The dry baroclinic adjustment hypothesis can be ruled out for $T_{m} \geq 20^{\circ} \mathrm{C}$, but it is impossible to distinguish between the dry and moist scaling theories with $T_{m} \leq 15^{\circ} \mathrm{C}$. Since there is no evidence for a regime transition with the moist scaling theory, the simplest explanation would appear to be that moisture controls the static stability in all cases for the full GCM as well, as it does in the idealized GCM. Shifts of eddies into colder (and less moist) latitudes and into latitudes where the $f / \beta$ factor is larger causes the dry scaling theory to work better in the full GCM. In this model it is also possible to rule out alternative moist hypotheses.

There are two outstanding problems of interest that are suggested by this work, which we plan to study in detail next. First, we have found in a previous study (Frierson 2006) that land surfaces are a primary complicating factor. With the influence of moist convection on static stability better established for the aquaplanet case, we plan next to study the influence of a land surface on the static stability. The lack of availability of moisture is likely to limit the influence of moist convection over and downwind of land. Further, for changes such as global warming or the seasonal cycle, the different heat capacity of land is likely to be an important factor as well. The land surface becomes much colder in winter, and warms more in the summer and with global warming. The effect of these factors on static stability and midlatitude dynamics in general will be interesting to study in an idealized context.

Finally, another important result that we have mentioned here is the meridional shifts of the jet with mean temperature and temperature gradient in the two models. This is a problem of fundamental importance, and one that climate modeling centers struggle with often, to get the mean storm tracks in the proper location. It is quite possible that the quantities we study here are relevant in determining the jet shift. For instance, the static stability can easily influence the position of the jet stream by reducing baroclinic growth rates (the maximum Eady growth rate, e.g., is inversely proportional to the static stability), thereby stabilizing baroclinic eddies at lower latitudes. The fact that the two models considered here have different jet locations for many of the simulations may mean that the idealized GCM is not 
very suitable for study of the jet latitude. However, the trend with mean temperature is found in both models, to a somewhat similar amount. Use of two-band radiative transfer, which can have much of the simplicity of the gray model with a more realistic tropopause, may be useful in bridging the gap between these two models. A detailed study of the effect of tropopause height, temperature gradients, static stability, and other factors is warranted within these models.

Acknowledgments. We thank Rodrigo Caballero for providing the full GCM simulation data, and Ray Pierrehumbert for helpful discussions. This work is supported by the NOAA Climate and Global Change Postdoctoral Fellowship, administered by the University Corporation for Atmospheric Research. This research is also supported in part by the Climate Systems Center of the University of Chicago, under National Science Foundation Grant ATM-0121028.

\section{REFERENCES}

Betts, A. K., 1986: A new convective adjustment scheme. Part I: Observational and theoretical basis. Quart. J. Roy. Meteor. Soc., 112, 677-692.

__ , and M. J. Miller, 1986: A new convective adjustment scheme. Part II: Single column tests using GATE wave, BOMEX, ATEX, and arctic air-mass data sets. Quart. J. Roy. Meteor. Soc., 112, 693-709.

Caballero, R., and P. L. Langen, 2005: The dynamic range of poleward energy transport in an atmospheric general circulation model. Geophys. Res. Lett., 32, L02705, doi:10.1029/ 2004 GL021581.

Chen, G., I. M. Held, and W. A. Robinson, 2007: Sensitivity of the latitude of the surface westerlies to surface friction. J. Atmos. Sci., 64, 2899-2915.

Emanuel, K. A., 1988: Observational evidence of slantwise convective adjustment. Mon. Wea. Rev., 116, 1805-1816.

Frierson, D. M. W., 2006: Robust increases in midlatitude static stability in simulations of global warming. Geophys. Res. Lett., 33, L24816, doi:10.1029/2006GL027504.

- 2007: The dynamics of idealized convection schemes and their effect on the zonally averaged tropical circulation. $J$. Atmos. Sci., 64, 1959-1976.

— I. M. Held, and P. Zurita-Gotor, 2006: A gray-radiation aquaplanet moist GCM. Part I: Static stability and eddy scale. J. Atmos. Sci., 63, 2548-2566.

,-- , and,- 2007a: A gray-radiation aquaplanet moist GCM. Part II: Energy transports in altered climates. $J$. Atmos. Sci., 64, 1680-1693.

— J. Lu, and G. Chen, 2007b: The width of the Hadley circulation in simple and comprehensive general circulation models. Geophys. Res. Lett., 34, L18804, doi:10.1029/ 2007GL031115.

Fu, Q., C. M. Johanson, J. M. Wallace, and T. Reichler, 2006:
Enhanced mid-latitude tropospheric warming in satellite measurements. Science, 312, 1179.

Held, I. M., 1982: On the height of the tropopause and the static stability of the troposphere. J. Atmos. Sci., 39, 412-417.

Jacob, R., 1997: Low frequency variability in a simulated atmosphere ocean system. Ph.D. thesis, University of WisconsinMadison, 155 pp.

Juckes, M. N., 2000: The static stability of the midlatitude troposphere: The relevance of moisture. J. Atmos. Sci., 57, 30503057.

Kiehl, J. T., J. J. Hack, G. B. Bonan, B. A. Boville, B. P. Brieglieb, D. L. Williamson, and P. J. Rasch, 1996: Description of the NCAR Community Climate Model (CCM3). NCAR Tech. Note NCAR/TN-420+STR, 152 pp.

Korty, R. L., and T. Schneider, 2007: A climatology of the tropospheric thermal stratification using saturation potential vorticity. J. Climate, 20, 5977-5991.

Lorenz, D. J., and E. T. DeWeaver, 2007: The tropopause height and the zonal wind response to global warming in the IPCC scenario integrations. J. Geophys. Res., 112, D10119, doi:10.1029/2006JD008087.

Lu, J., G. A. Vecchi, and T. Reichler, 2007: Expansion of the Hadley cell under global warming. Geophys. Res. Lett., 34, L06805, doi:10.1029/2006GL028443.

Polvani, L. M., and P. J. Kushner, 2002: Tropospheric response to stratospheric perturbations in a relatively simple general circulation model. Geophys. Res. Lett., 29, 1114, doi:10.1029/ 2001 GL014284.

Santer, B. D., and Coauthors, 2003: Contributions of anthropogenic and natural forcing to recent tropopause height changes. Nature, 301, 479-483.

Schneider, T., 2004: The tropopause and the thermal stratification in the extratropics of a dry atmosphere. J. Atmos. Sci., 61, $1317-1340$

, and C. C. Walker, 2006: Self-organization of atmospheric macroturbulence into critical states of weak nonlinear eddyeddy interactions. J. Atmos. Sci., 63, 1569-1586.

Seidel, D. J., and W. J. Randel, 2006: Variability and trends in the global tropopause estimated from radiosonde data. J. Geophys. Res., 111, D21101, doi:10.1029/2006JD007363.

Stone, P. H., 1978: Baroclinic adjustment. J. Atmos. Sci., 35, 561571.

Thuburn, J., and G. C. Craig, 1997: GCM tests of theories for the height of the tropopause. J. Atmos. Sci., 54, 869-882.

Williams, G. P., 2006: Circulation sensitivity to tropopause height. J. Atmos. Sci., 63, 1954-1961.

Xu, K.-M., and K. A. Emanuel, 1989: Is the tropical atmosphere conditionally unstable? Mon. Wea. Rev., 117, 1471-1479.

Yin, J. H., 2008: A consistent poleward shift of the storm tracks in simulations of 21st century climate. Geophys. Res. Lett., 32, L18701, doi:10.1029/2005GL023684.

Zurita-Gotor, P., 2008: The sensitivity of the isentropic slope in a primitive equation dry model. J. Atmos. Sci., 65, 43-65.

, and R. S. Lindzen, 2007: Theories of baroclinic adjustment and eddy equilibration. The Global Circulation of the Atmosphere: Phenomena, Theory, Challenge, T. Schneider and A. Sobel, Eds., Princeton University Press. 